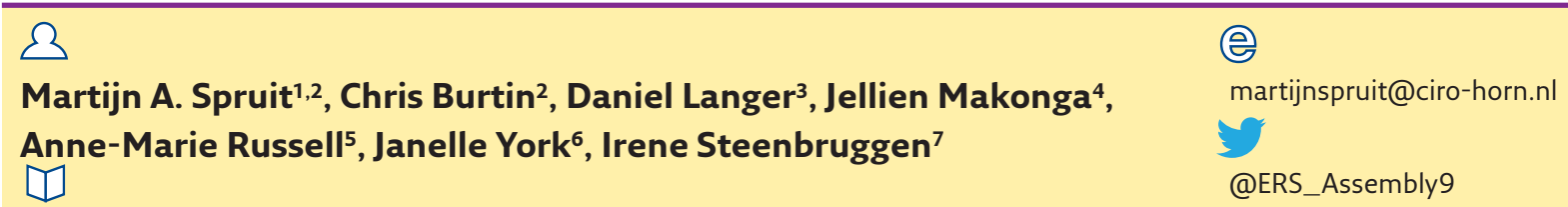

'Dept of Research and Education, CIRO, Horn, The Netherlands. ${ }^{2}$ Faculty of Medicine and Life Sciences, Rehabilitation Research Centre, Biomedical Research Institute, Hasselt University, Diepenbeek, Belgium. ${ }^{3} \mathrm{KU}$ Leuven-University of Leuven, Faculty of Kinesiology and Rehabilitation Sciences, Dept of Rehabilitation Sciences, Research Group for Cardiovascular and Respiratory Rehabilitation, Leuven, Belgium. ${ }^{4}$ Longfunctie Afdeling, Meander Medisch Centrum, Amersfoort, The Netherlands. ${ }^{5}$ National Heart and Lung Institute, Imperial College and Royal Bromton Hospital, London, UK. ${ }^{6}$ Faculty of Biology, Medicine and Health, University of Manchester and The Christie NHS Foundation Trust, Manchester, UK. 'Pulmonary Laboratory, Isala, Zwolle, The Netherlands.

\title{
Assembly 9: allied respiratory professionals
}

\section{Meet the Assemblies}

Cite as: Spruit MA, Burtin C, Langer D, et al. Assembly 9: allied respiratory professionals. Breathe 2016; 12: e113-e114.
Allied respiratory professionals are very important in daily clinical practice. Respiratory function technologists provide doctors with valid lung function test results to enable an accurate diagnosis and long-term monitoring. Moreover, physical fitness testing (i.e. cardiopulmonary exercise testing, functional exercise tests, and respiratory and peripheral muscle strength testing), and the initiation and ongoing support of nonpharmacological therapies (i.e. pulmonary rehabilitation, physiotherapy, collaborative selfmanagement, etc.) are mostly done by respiratory function technologists, physiotherapists, nurses or a combination thereof. Therefore, allied respiratory professionals have joined forces in ERS Assembly 9. This Assembly is specifically dedicated to providing allied respiratory professionals with their own international forum, and to emphasise the importance of their clinical and scientific contributions. To keep up to date with ideas and links to interesting articles, we invite you to follow us on Twitter at @ERS_Assembly9.

\section{1) Respiratory function technologists/scientists}

Members of Group 9.1 are active in various task forces as experts on the use of multiple technologies in respiratory healthcare. This group has more than 200 members, and has a very active core group participating in different courses, task forces and activities at the ERS International Congress. Yearly, Group 9.1 receives about 75 abstracts, many from young new members, but there is also a group of experienced colleagues sending in abstracts on a regular basis, supplying us with the scientific backbone for the international lung function standards and guidelines.

Group 9.1 aims to collaborate closely with Groups 9.2 (physiotherapists) and 9.3 (nurses), as well as ERS Groups outside Assembly 9: Group 5.2 (monitoring airway disease), Group 7.2 (paediatric allergy and asthma), Groups 6.1 and 6.2 (occupation and epidemiology), and group 4.1 (clinical respiratory physiology, exercise and functional imaging).

Group 9.1 developed the HERMES curriculum for the Spirometry Driving Licence, which runs in various countries. This course uses many different teaching formats like workshops, ice-breakers, and portfolio and practical assessment. The course has also an annual Train the Trainer session at the ERS International Congress for those who want to become spirometry trainers.

For the European Lung Foundation (ELF), Group 9.1 members attend public spirometry events. At the Congress, we are always busy carrying 
out spirometry in market places and on famous shopping streets. Sometimes we go to Brussels to inform Members of the European Parliament of the risks of smoking and the political interventions that need to be taken.

\section{2) Physiotherapists}

Group 9.2 is young, international and dynamic. It currently consists of almost 300 members, of whom almost $70 \%$ are below the age of 40 . All five continents are represented, which makes the group an ideal platform for exchanging ideas with colleagues from all over the world. To further facilitate this exchange of ideas between members, an ERS physiotherapy Facebook group (https://www. facebook.com/groups/1737074866545251/) has recently been established by Group 9.2 officers with the support of ELF. This group has attracted already more than 350 participants since it was established in June 2016. The platform is intended for lively discussions and exchange of information between physiotherapy colleagues with an explicit interest in respiratory diseases from all over the world. The annual ERS International Congress is of course an important activity of Group 9.2 and an ideal opportunity to meet colleagues in person. Indeed, many Group 9.2 members attend and participate actively in the various relevant sessions. Our group member meetings are typically very well attended. These meetings are mainly used for an update of Group 9.2 activities but also for other specific profession-related topics. Group 9.2 was heavily involved in the development of the soon-tobe-published HERMES Physiotherapy educational curriculum. Outside of Congress hours, Group 9.2 has established an annual tradition of organising a "physio night out". During the ERS 2016 Congress, more than 100 participants joined a walk through London followed by a comfortable dinner at a local pub, extended by some drinks afterwards.

\section{3) Nurses}

The ERS nursing group is populated by vibrant, active nurses from around the world. Group 9.3 is relatively few in number, although its membership has progressively increased from 64 in 2014 to more than 80 in 2016. The nursing group is represented across a variety of ERS activities, including the ERS Colleges of Experts, contributing to reviewing applications for ERS Fellowships and travel awards; they also contribute to task force activities and ERS educational courses (e.g. the interstitial lung disease course in Heidelberg, Germany). We are very proud that, Saskia Weldam, a nurse from the Netherlands, has recently been appointed to and will represent nursing interests on the ELF Professional Advisory Committee.

Mirroring the increase in nurse membership, there is a gradual increase in the number of abstracts submitted by nurses that are accepted for the ERS Congress. A total of 41 abstracts was presented at Congress in London in 2016, enabling us to populate three dedicated nursing sessions: one oral presentation session, one thematic poster session and one poster discussion session, which were well attended. The topics were wide ranging, in keeping with the spectrum of the clinical and research activities of our membership.

The Travel Grant for Best Abstract, London 2016, was awarded to nurse Caroline Stridsman (Sweden) for her excellent project "Girls with asthma have worse quality of life than boys - a population based study". Group 9.3 officers will continue to engage with the Group 9.3 members and the global nursing community to ensure that we continue to grow.

\section{The future}

Please do join Assembly 9, not only to increase the visibility of the allied respiratory professionals, but also to improve the quality of allied healthcare for patients with chronic lung diseases. 